\title{
Correction to: Nutritional fitness of a reduviid predator Rhynocoris marginatus (fab.) (Hemiptera: Reduviidae) using biological traits and macromolecules of pests
}

\author{
Kitherian Sahayaraj $^{1}$ • Priya Dharshini Lakshmanan ${ }^{1} \cdot$ Yêyinou Laura Estelle Loko ${ }^{2}$ \\ Published online: 28 October 2020 \\ (C) African Association of Insect Scientists 2020
}

\section{Correction to: International Journal of Tropical Insect Science} https://doi.org/10.1007/s42690-020-00248-y

In the original publication, the names of the second and third author were scrambled. The original article has been corrected and the proper representation of the authors' names and their affiliation is also published here.

Publisher's note Springer Nature remains neutral with regard to jurisdictional claims in published maps and institutional affiliations.

The online version of the original article can be found at https://doi.org/ 10.1007/s42690-020-00248-y

Kitherian Sahayaraj

ksraj48@gmail.com

1 Crop Protection Research Centre, Department of Zoology, St. Xavier's College, Palayamkottai, Tirunelveli, Tamil Nadu 627002, India

2 Laboratory of Applied entomology (LEnA), National High School of Applied Biosciences and Biotechnologies (ENSBBA), National University of Sciences, Technologies, Engineering and Mathematics, BP 14, Dassa, Benin 